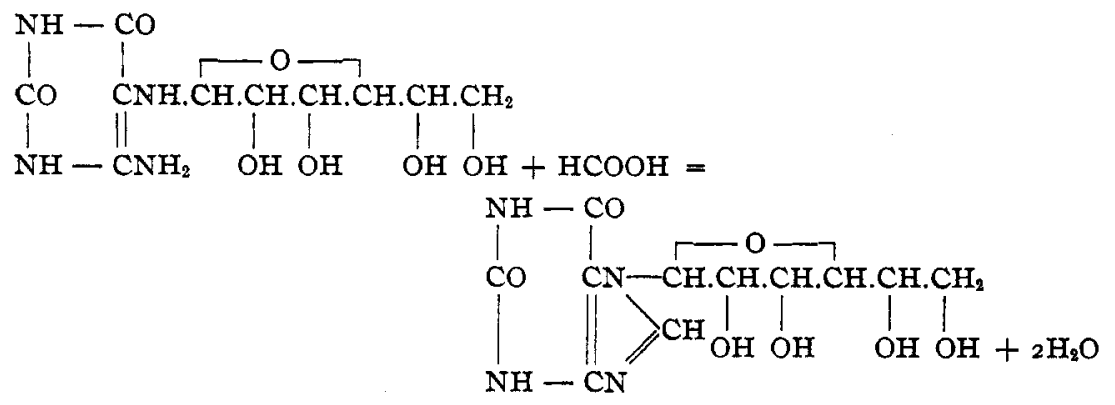
XVI.

New investigations are now in progress and we hope to obtain new and important data bearing on these interesting problems.

Naw HAVEN, CoNn.

[CONTRIBUTIONS FROM THE SHEFFIELD ChEMICAI, LABORATORY OF YALE UNIVERSITY.]

\title{
RESEARCHES ON PYRIMIDINES. LXVI. THE FORMATION OF PYRIMIDINES FROM DIETHYL AMINOMALONATE AND AMINO MALONICNITRILE.
}

\section{By Treat B. Johnson and Ben H. Nicoler.}

Received November 24, 1913. mental Part.

1. Introduction. 2. Diethyl Aminomalonate and its Derivatives. 3. Experi-

\section{Introduction,}

In the previous paper ${ }^{1}$ the assumption has been expressed that pyrimidines of the barbituric acid series may be the precursors of purines in plant growth, and we discussed new evidence that dialuric acid and uramil may be the representatives of this series, which are involved in these changes. It is easily conceivable how both of these pyrimidines, if formed, might undergo condensations with urea or formamide ${ }^{2}$ and be transformed into purine compounds, consequently it is of especial interest to consider how cyclic compounds of this type might be formed in growth from simpler substances.

The question of the relation of hydrocyanic acid to the mechanism of the natural synthesis of purines is an interesting problem, concerning

1 Johnson, This Journal, 36, 337 (1914).

${ }^{2}$ It is of especial interest to note here that W. Löb (Ber., 46, 684) has recently reported a synthesis of aminoacetic acid from formamide and water vapor, under the influence of the silent electrical discharge. Oxamide was also formed under the same conditions. The synthesis was therefore a complete one and the apparent course of the reaction was as follows:

${ }_{2} \mathrm{HCONH}_{2} \stackrel{\text { 一 }}{\longrightarrow} \mathrm{NH}_{2} \mathrm{CO} . \mathrm{CONH}_{2} \stackrel{+\mathrm{H}_{3} \mathrm{O}}{\longrightarrow} \mathrm{NH}_{2} \mathrm{COCOONH}_{4} \stackrel{+2 \mathrm{H}_{3}}{\longrightarrow} \mathrm{NH}_{2} \mathrm{CH}_{2} \mathrm{COONH}_{4}$. Though the yield of glycocoll was small, Löb considers this the nearest approach yet made to the actual conditions of plant synthesis. It is not improbable that formamide may play an important part in other natural syntheses (T. B. J.). 
which practically nothing is known. Throughout the history of this chapter of biochemistry can be traced the feeling, however, that this organic acid, which is known to occur in a free condition in plants, plays a far more important part in these changes than it is customary to assume for it. Adenine, indeed, is a polymeric modification of prussic acid and hypoxanthine is formed easily by simple hydrolysis of this aminopurine. Gautier $^{1}$ recognized the biological significance of hydrocyanic acid in nature's processes and in his interesting paper, in which he describes his supposed synthesis of xanthine and methyl xanthine from prussic acid, ${ }^{2}$ he writes as follows: "Le méchanisme des synthéses dout je viens de donner l'apercu, me parait trés rapproché, sinon identique, de celui qui se passe chez les végétaux," and also in the same article: "Je dois ajouter en terminant, que ces agrégations d'edifices organiques' complexes peuvent se produire même à froid, quoique avec plus de lenteur, sous l'influence des alcalis ou des sels alcalins agissant sur $\mathrm{CNH}$, nouveau rapprochement de ces synthéses avec celles qui se font chez les végétaux." Notwithstanding the fact that Gautier's attempts to synthesize purines from prussic acid were unsuccessful, and that others have been tempted to give too much importance to the protein molecule of hydrocyanic acid, more reasonable syntheses are not wanting.

It is a well known fact that hydrocyanic acid is very susceptible to polymerization, and of all the transformations which it is known to undergo, that in which three molecules unite to form aminomalonic nitrile $\mathrm{I}$, ${ }_{3} \mathrm{HNC}=\mathrm{NH}_{2} \mathrm{CH}(\mathrm{CN})_{2}$.

I.

is probably the best understood. Lange ${ }^{3}$ was apparently the first to observe this unique transformation while trying to make hydrocyanic acid add to epichlorhydrin. He observed no evidence of the formation of the

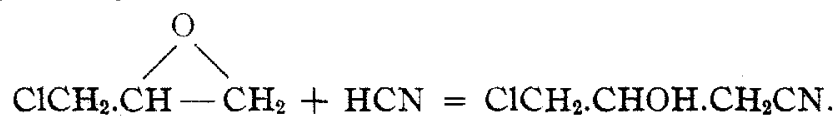

II.

hydroxynitrile II, but succeeded in isolating a substance having the formula $\mathrm{C}_{3} \mathrm{H}_{3} \mathrm{~N}_{3}$. On hydrolysis, this interesting product gave an acid, which evolved carbon dioxide, on heating, and was transformed into aminoacetic acid IV. Its structure, therefore, was established by this observation.
$\mathrm{NH}_{2} \mathrm{CH}(\mathrm{CN})_{2} \longrightarrow \mathrm{NH}_{2} \mathrm{CH}(\mathrm{COOH})_{2} \rightarrow \mathrm{CO}_{2}+\mathrm{NH}_{2} \mathrm{CH}_{2} \mathrm{COOH}$. I. III. IV.

Hörrmann ${ }^{4}$ and Lespieau ${ }^{5}$ later studied this polymerization reaction of

1 Bull. soc. chim., 42, 44I (1884).

${ }^{2}$ Loc. cit.

${ }^{8}$ Ber., 6, 99 (1873).

4 Ibid., 12, 23 (1879).

- Compt. rend., 127, 965 (1898). 
Lange's and obtained the desired addition product namely, $\gamma$-chloro- $\beta$ hydroxybutyronitrile II, without observing the formation of any aminomalonic nitrile. The observation, of Lange was confirmed in 1874 by Wippermann. ${ }^{1}$ This investigator found that this characteristic polymerization was greatly favored by small quantities of alkaline salts, especially the cyanide, hydroxide or carbonate of potassium, sodium and ammonium. He also confirmed the aminomalonic nitrile structure, which was already made probable by the results obtained by Lange. Lescoeur and Rigaut ${ }^{2}$ likewise investigated the catalytic effect of potassium cyanide on prussic acid, buit added little to what was already known. The latest work on the polymerization of the acid is that of Bamberger and Rudolf, ${ }^{3}$ who were finally able to describe a method for the preparation of the nitrile which gave over $50 \%$ of the theoretical yield. Here again, however, the result was entirely unexpected, being noticed in the course of an unsuccessful attempt to add hydrocyanic acid to dimethylaniline oxide. Whether the function of the aniline oxide is a catalytic one is not known. It is interesting to note, also, in this connection that a reaction, somewhat similar to this characteristic polymerization of hydrocyanic acid, has recently been described by Decker and Becker. ${ }^{4}$ They observed, for example, that formylphenylethylamine, $V$, when heated with phosphorus pentachloride, is transformed into phenylethylaminomalondiphenylethylamide, VI, with evolution of water.

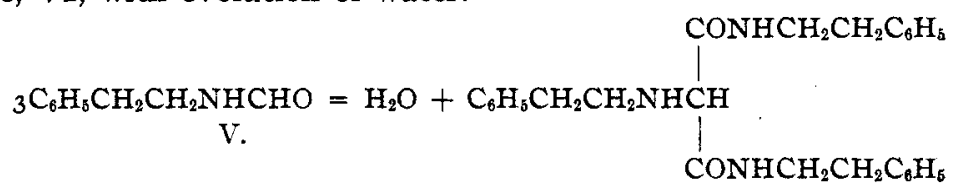

VI.

This most interesting and long known fact that prussic acid is so susceptible to polymerization, under the influence of specific reagents, suggests that the same transformation of the acid may likewise take place under catalytic influence in nature. The aminomalonic nitrile, if formed, would then be a combination favorable for further syntheses. Theoretically it might lead to pyrimidine combinations in two ways, namely, either condense with urea in a manner analogous to that of malonic nitrile, which was investigated by Traube, ${ }^{5}$ or undergo saponification to the corresponding acid and then condense with urea to give uramil. The further condensation of a diaminopyrimidine, VII, or uramil, IX, with urea are reactions requiring no special justification. The complete synthesis of uric

1 Ber., 7, 767 .

2 Compt. rend., 69, 310 (1879).

${ }^{3}$ Ber., 35, 1082 (1902).

4 Ann., 382, 369 (I9I I).

' Ibid., 33I, 8o (1904); Wheeler and Jamieson, Am. Chem. J., 32, 342. 
acid, for example, from hydrocyanic acid and urea, might theoretically be accomplished according to the stages expressed by the following equations:

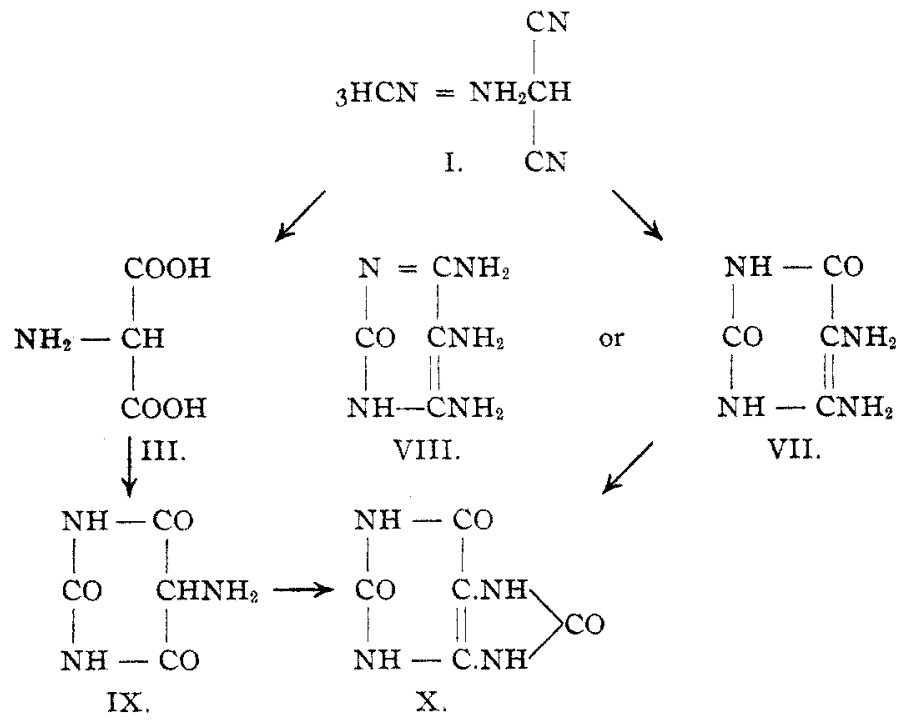

We have now prepared aminomalonic nitrile $\mathrm{I}$, according to Bamberger and Rudolf's directions and find that it condenses with thiourea, in the presence of sodium ethylate, forming a pyrimidine. The triaminopyrimidine, however, was not obtained as expected, but Traube's ${ }^{1}$ 2-thio-6oxy-4,5-diaminopyrimidine, XIII. The yield was small, owing to much decomposition. That this diaminopyrimidine is formed is probably due to the fact that the intermediate product of the condensation XI, undergoes hydrolysis, giving the acid XII, which then condenses normally, forming the diaminopyrimidine.

These changes may be represented as follows:

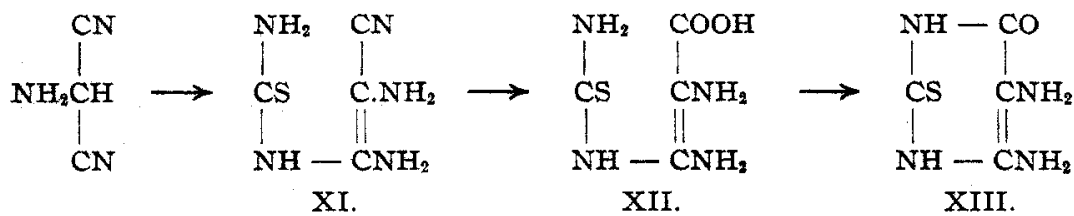

That pyrimidines of this type can easily be converted into purines has been established by the work of Traube ${ }^{2}$ and Johns. ${ }^{3}$

Dr. Shephard ${ }^{4}$ of this laboratory has shown that uramils and thiouramils

Ann., 33I, 75.

Loc. cit.

${ }^{3}$ Johns and Hogan, J. Biol. Chem., I4, 299.

4 Thrs Journal, 35, 994. 
can be obtained easily by condensing esters of substituted aminomalonic acid with urea and thiourea. We now find that the substitution of the basic amino group into diethylmalonate does not prevent the condensation of this ester with ureas. The amino ester combined with thiourea giving 2-thiouramil, which has already been prepared from thiourea and diethyl phthalimidomalonate. ${ }^{1}$ Descriptions of these condensations, which are of biochemical interest, and of some new derivatives of aminomalonic acid are given in the following chapters of this paper:

\section{Diethyl Aminomalonate and Its Derivatives.}

Aminomalonic acid was first described by Baeyer, ${ }^{2}$ in 1864 , who obtained it by reducing nitrosomalonic acid with sodium amalgam. He analyzed a number of its salts and found that heat converted the free acid smoothly into glycocoll. The same acid was later made by Piloty and Finckh ${ }^{3}$ by hydrolysis of uramil with barium hydroxide, a reaction which von Baeyer had tried in vain. Ruhemann and Orton ${ }^{4}$ prepared the acid by alkaline hydrolysis of the amide, as did also Piloty and Neresheimer, ${ }^{5}$ in 1906 . Lutz ${ }^{6}$ in the same year, prepared the acid by action of ammonia on monohalogen derivatives of malonic acid.

The free diethylaminomalonate is unknown. Piloty and Neresheimer ${ }^{7}$ prepared the hydrochlorides of both the methyl and ethyl esters. They reduced nitrosomalonic esters, dissolved in ether, with aluminium amalgam, and precipitated the hydrochloride of the amino esters by passing dry hydrochloric acid gas into the ether solution. Ureidomalonic acid, for

$\mathrm{NH}_{2} \mathrm{CO} . \mathrm{NH} . \mathrm{CH}(\mathrm{COOH})_{2}$

example, has never been synthesized directly.

For our investigation, we prepared the diethyl aminomalonate according to Piloty and Neresheimer's ${ }^{7}$ directions with slight modifications. They recommend the reduction of the nitrosoester in ether solution with aluminium amalgam. The reaction is controlled by the addition of water at a rate just sufficient to keep the amalgam reacting smoothly. The yield obtained is about $5 \mathrm{I} \%$, but, as they justly remark, the product clings tenaciously to the aluminum hydroxide, which must be extracted repeatedly with ether. This difficulty was found to be so real, and the repeated extraction of the bulky precipitate $\left(\mathrm{Al}(\mathrm{OH})_{3}\right)$ with ether so tedious without the use of proper apparatus, that a new method of reduction was sought.

${ }_{1}^{1}$ Johnson and Shepard, ThIs JourNaL, 35, 994.

${ }^{2}$ Anx., I3I, 29 I.

${ }^{3}$ Ibid., 333, $7 \mathrm{r}$.

$4 \mathrm{~J}$. Chem. Soc. (London), 67, 1002.

'Ber., 39, 514.

${ }^{6}$ Ibid., 35, 2549.

${ }^{7}$ Loc. cit. 
The reduction was finally accomplished by the use of hydrogen sulfide in alkaline solution. The application of this reducing agent to aliphatic compounds has apparently been very limited, and confined practically to the reduction of violuric acid derivatives. ${ }^{1}$ In these cases, hot ammonium sulfide could be used. In the present instance, any excess of ammonia would lead to the formation of the acid amide, and the application of heat would produce hydrolysis. Nitrosomalonic ester ${ }^{2}$ was therefore dissolved in water with exactly a molecular proportion of potassium hydroxide, to form the soluble potassium salt. Hydrogen sulfide was then conducted into the cold solution for several hours, and the ester of the aminoacid extracted with ether. It was then isolated in the form of its hydrochloride by saturating the ether with hydrochloric acid gas. An almost pure hydrochloride was obtained in this manner and the yield was $45 \%$ of the theoretical. To compensate for the slightly smaller yield than that given by Piloty and Neresheimer, ${ }^{3}$ this method is simpler and more convenient, and requires much less attention.

It was found that unless alkali was present, hydrogen sulfide caused no appreciable reduction. An alcoholic solution of ethyl nitrosomalonate gave only a trace of sulfur after saturating with hydrogen sulfide for several hours. This is in accordance with Baeyer' $\mathrm{s}^{4}$ observation that this gas has no action on the neutral water or alcoholic solution of dilituric acid, XIV. On the other hand Traube ${ }^{5}$ has reported the remarkable case of the reduction of 2 -iminovioluric, XV, with hydrogen sulfide in hydrochloric acid solution.<smiles>[X][C@H]1NC(=O)NC(=O)[C@@H]1[N+](=O)[O-]</smiles><smiles>[Y10]NC(=N)C(=O)O</smiles>

While nitrosomalonic ester was reduced under the conditions described, diethyl nitromalonate under the same conditions was practically unaffected. This result is the more surprising in connection with the behavior of aromatic nitro and nitroso compounds toward ammonium sulfide. An interesting observation is that of Sachs and Kempf, ${ }^{6}$ for instance, who have reported that when 2,4-dinitrobenzaldoxime, XVI, is reduced with an excess of warm ammonium sulfide, the products formed are first 2nitro-4-aminobenzaldoxime, XVII, and finally, 2,4-diaminobenzaldoxime,

1 Traube, $A n n ., 33$ r, 64.

2 Bouveault and Wahl, Compt. rend., 137, r96 (1903).

${ }^{3}$ Loc. cit.

Ann., 127, 223.

's Ber., 26, 255 r.

I Ibid., 35, 1224. 
XVIII. This oxime could not be further reduced by this method. The order of stability, therefore, was just the reverse of that found in the aliphatic series.<smiles>O=C1CCC([N+](=O)[O-])CC1=O</smiles>

XVI.<smiles>N[C@H]1CCC[C@@H](NO)C1=O</smiles>

XVII.<smiles>N[C@H]1CCN[C@@H]1O</smiles>

XVIII.

As previously stated, diethylaminomalonate was found to show the normal condensation reaction of malonic esters. It condensed with thiourea, in the presence of sodium ethylate, giving a good yield of 2thiouramil, XXV. The isomeric 6-thiouramil, XXVII, has been prepared by Fischer and $A c^{1}$ and also by Weidel and Niemilovicz. ${ }^{2}$ When digested with potassium cyanate solution in the usual way, the thiouramil<smiles>[R14]C1CC(=O)N[AsH]1</smiles><smiles>CCOC(=O)C(C(=O)OCC)C(C(=O)OCC)C(=O)OCC</smiles>
$\mathrm{XX}$.

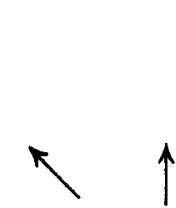<smiles>C[12CH3]</smiles><smiles>CCOC(=O)C(NC(=O)NCc1ccccc1)C(=O)OCC</smiles>

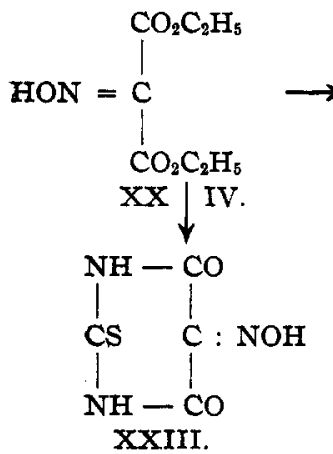<smiles>NC1NC(=O)NC1=O</smiles>

XXVII.

I Ann., 288, 55 .

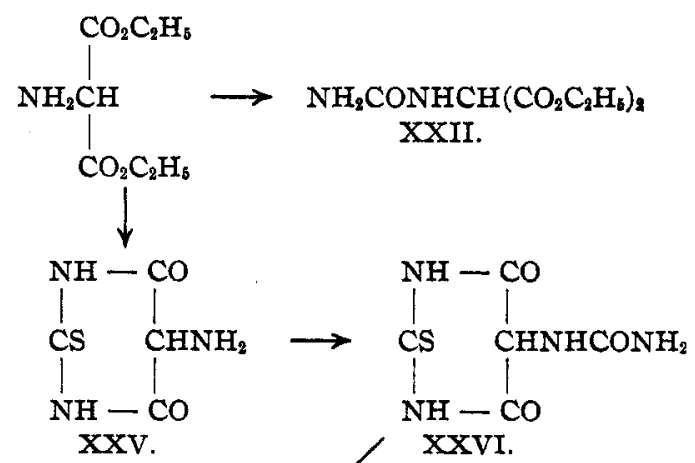

2Monats. f. Chem., 16, 721. 
was converted into 2-thiopseudouric acid, XXVI, which completes the list of possible monothiopseudouric acids. Attempts to close this acid to 2-thiouric acid, XXVIII, either by boiling with hydrochloric acid or by fusion with oxalic acid, were unsuccessful. Fischer and $\mathrm{Ach}^{1}$ indeed, found the same difficulty with 6-thiopseudouric acid. Johns and Hogan, ${ }^{1}$ of this laboratory, have prepared this acid by heating 2-thio-6-oxy-4,5diaminopyrimidine with urea. Diethyl nitrosomalonate, XXIV, condensed with thiourea giving 2 -thiovioluric acid, XXIII.

Since free diethylmalonate is a liquid and its hydrochloride melts with decomposition, it was therefore desirable to obtain characteristic derivatives with definite melting points and small solubilities, that might serve for the isolation and certain identification of small quantities of the ester. The urethane, $\mathrm{XX}$, and the benzoylthiourea ester, XXI, therefore, were prepared and found to serve this purpose well. Either of these compounds can be made and purified from a gram or less of the diethyl aminomalonate. The acylthiourea derivatives on heating with hydrochloric acid are converted into 2 -thiohydantoin, XIX.

Diethylureidomalonate, XXII, was easily obtained by the action of cyanic acid on diethyl aminomalonate. An attempt, however, to condense this with urea to form pseudouric acid was unsuccessful. These various changes are represented by the preceding formulas.

\section{Experimental Part.}

Diethyl Aminomalonate from Diethyl Nitrosomalonate by Reduction with Hydrogen Sulfide.-The diethyl nitrosomalonate was prepared according to the method of Bouveault and Wahl. ${ }^{2}$ The crude ester was used for reduction and contained, by analysis, $80 \%$ of the pure nitroso compound. The method of reduction was as follows: Ten grams of the nitrosomalonate were dissolved in $30 \mathrm{cc}$. of water containing 3.0 grams of potassium hydroxide, the solution cooled in an ice bath, and then saturated with hydrogen sulfide gas. Sulfur soon began to separate and after 10 to 12 hours the solution was filtered and extracted repeatedly with ether. This ether extract, after drying with magnesium sulfate, was evaporated, leaving an oil containing diethyl aminomalonate, together with any unaltered diethyl malonate and nitroso ester and some sulfur. This crude oil was finally dissolved in anhydrous ether, filtered from sulfur, and the solution saturated at a low temperature with dry hydrochloric acid gas. The colorless, crystalline hydrochloride of the amino ester separated at once, practically pure. The yield was 4.7 grams, corresponding to $47 \%$ of the theoretical. In working up quantities of the nitrosomalonic ester larger than 20 grams, the yield was considerably smaller,

\footnotetext{
${ }^{1}$ Loc. cit.

2 Compt. rend., $\mathbf{1 3 7}, 196$.
} 
probably, on account of the difficulty of getting sufficient hydrogen sulfide absorbed before a part of the ester undergoes hydrolysis.

An attempt to prepare the ethyl ester of aminomalonic acid by reduction of diethyl nitromalonate with hydrogen sulfide was unsuccessful. Ten and five-tenths grams of the ammonium salt of the nitro ester, melting with decomposition at $156^{\circ}$, were dissolved in four parts of water, and hydrogen sulfide passed into the solution for I6 hours. As no sulfur had separated during this treatment, a molecular proportion of potassium hydroxide was added, and the gas again conducted into the solution for I6 hours. There was no precipitation of sulfur. On acidifying the solution 0.1 gram of sulfur separated. No diethyl aminomalonate hydrochloride could be obtained from the ether extract, but on passing in ammonia gas, 6.0 grams of the ammonium salt of unaltered diethyl nitromalonate separated.

Diethyl Carbethoxyaminomalonate, $\mathrm{C}_{2} \mathrm{H}_{5} \mathrm{OOC} . \mathrm{NHCH}\left(\mathrm{COOC}_{2} \mathrm{H}_{6}\right)_{2}$. -To a solution of 3.0 grams of the hydrochloride of diethyl aminomalonate and 5.0 grams of sodium bicarbonate in $25 \mathrm{cc}$. of water, were added 2.0 grams of ethyl chloroformate in $5 \mathrm{cc}$. of benzene. The mixture was then shaken as long as carbon dioxide was evolved, and after standing at ordinary temperature for several hours (Io) was extracted with ether. The residue obtained after evaporation of the ether crystallized from dilute alcohol in long, colorless needles melting sharply at $63^{\circ}$. The urethane is very soluble in alcohol and ether and slightly soluble in water.

Calculated for $\mathrm{C}_{20} \mathrm{H}_{17} \mathrm{O}_{6} \mathrm{~N}: \mathrm{N}, 5.67$. Found: N, 5.5 $\mathrm{I}$.

Diethyl Benzoylthioureidomalonate, $\mathrm{C}_{6} \mathrm{H}_{5} \mathrm{CONH} . \mathrm{CSNHCH}\left(\mathrm{COOC}_{2} \mathrm{H}_{5}\right)_{2}$. - The ester from 2.0 grams of the hydrochloride of diethyl aminomalonate was liberated by adding 0.9 gram of sodium bicarbonate to a solution of the salt in $5 \mathrm{cc}$. of water. A slight excess of ethyl benzoyldithiocarbamate was then added in $20 \mathrm{cc}$. of alcohol. The solution was then warmed for an hour on the steam bath, and allowed to stand over night. The alcohol was then evaporated, when the ureido derivative was obtained as a semi-solid substance. This was dried on a porous plate. The yield was 2.9 grams, corresponding to $90 \%$ of the theoretical. This compound is readily soluble in warm alcohol and separates, on cooling, in rectangular plates, which melt at $123^{\circ}$. It is moderately soluble in ether and difficultly soluble in water. The ester is converted smoothly into 2-thiohydantoim when digested with hydrochloric acid.

Calculated for $\mathrm{C}_{15} \mathrm{H}_{18} \mathrm{O}_{6} \mathrm{~N}_{2} \mathrm{~S}: \mathrm{N}, 8.29$. Found: $\mathrm{N}, 8.2 \mathrm{I}$.

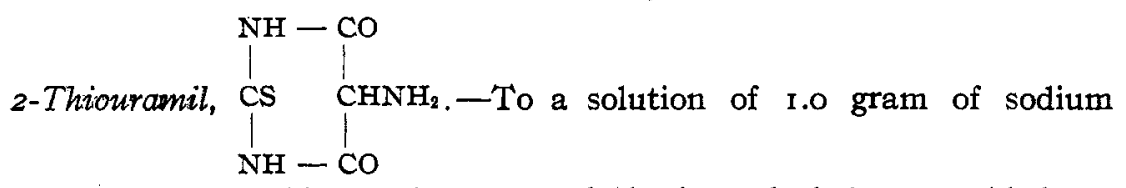

and $\mathbf{x} .5$ grams of thiourea in $40 \mathrm{cc}$. of absolute alcohol were added 3.0 
grams of the hydrochloride of diethyl aminomalonate, and the mixture boiled for three hours. The dark red sodium salt which separated was filtered off, dissolved in a little water and decomposed by addition of an excess of acetic acid. The pyrimidine separated as a yellow powder and weighed 1.6 grams, corresponding to $70 \%$ of the theoretical yield. It did not melt or decompose below $300^{\circ}$. The compound is very difficultly soluble in the common solvents and was purified by dissolving in alkali, decolorizing by digestion with bone coal, and then precipitating with acid from the hot solution. It was very difficult to remove the inorganic salts carried down with the precipitate.

Calculated for $\mathrm{C}_{4} \mathrm{H}_{5} \mathrm{O}_{2} \mathrm{~N}_{3} \mathrm{~S}: \mathrm{N}, 26.40$. Found: $\mathrm{N}, 25.9$.

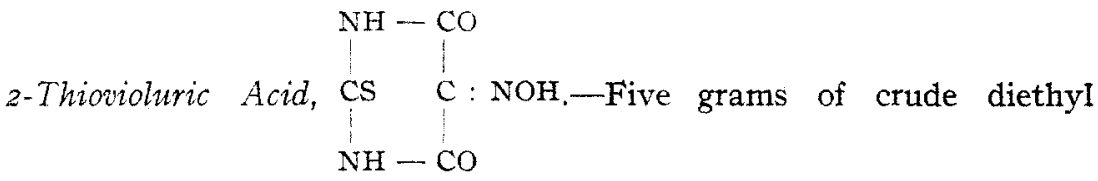

nitrosomalonate were condensed with thiourea in absolute alcohol containing 3 molecular proportions of sodium ethylate. After heating for three hours, the gelatinous, dark red sodium salt, which was formed, was filtered off, dissolved in water and the solution acidified, when 0.7 gram of a red powder deposited. This proved to be a mixture of the violuric acid with another product, probably thiobarbituric acid formed from a little malonic ester present in the original nitroso ester. The two were separated by warming with an aqueous solution of sodium bicarbonate; the violuric acid, being a much stronger acid than thiobarbituric, went into solution. On acidifying, the pure 2-thiovioluric acid separated as a yellow powder. It did not melt below $300^{\circ}$. The compound is difficultly soluble in all common neutral solvents. Boiled with water, it gives the latter a yellow color, but without dissolving appreciably. The pyrimidine dissolves in alkali, giving a yellow color.

Calculated for $\mathrm{C}_{4} \mathrm{H}_{3} \mathrm{O}_{3} \mathrm{~N}_{3} \mathrm{~S}: \mathrm{N}, 24 \cdot 36$. Found: $\mathrm{N}, 24.66$.

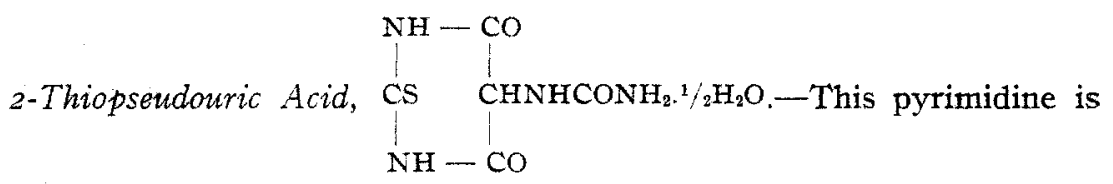

formed by warming 2-thiouramil in aqueous solution with potassium cyanate. On acidifying with hydrochloric acid (acetic acid gave no precipitate) the pyrimidine separated as a crystalline powder. The compound is very difficultly soluble in water and alcohol, but readily soluble in alkaline solutions. The pyrimidine deposits practically colorless, but when heated it loses its water of crystallization and becomes deep purple. When heated in a capillary tube it begins, below $200^{\circ}$, to assume a purple color; this becomes very intense until at about $270^{\circ}$ it begins to disappear. The 
color then becomes faintly yellow and remains so until decomposition sets in above $300^{\circ}$. The anhydrous pyrimidine dissolved in alkali giving a deep green solution, which became red when the solution was acidified with acetic acid. The addition of hydrochloric acid discharges the color and produces a precipitate of the pyrimidine.

Calculated for $\mathrm{C}_{6} \mathrm{H}_{6} \mathrm{O}_{3} \mathrm{~N}_{4} \mathrm{~S} .1 / 2 \mathrm{H}_{2} \mathrm{O}: \mathrm{N}, 26.48 ; \mathrm{H}_{2} \mathrm{O}, 4.26$.

Found:

$\mathrm{N}, 26.34 ; \mathrm{H}_{2} \mathrm{O}, 4.9$

Diethyl Ureidomalonate, $\mathrm{NH}_{2} \mathrm{CONH} . \mathrm{CH}\left(\mathrm{COOC}_{2} \mathrm{H}_{5}\right)_{2}$.-This compound is formed at once when potassium cyanate reacts in a concentrated aqueous solution with the hydrochloride of diethyl aminoacetate. The reaction is complete in $3-4$ minutes and the yield of ester is $75 \%$ of the theoretical. The urea is difficultly soluble in hot alcohol, from which it crystallizes, on cooling, in octahedra. It melts at $173^{\circ}$.

Calculated for $\mathrm{C}_{8} \mathrm{H}_{14} \mathrm{O}_{6} \mathrm{~N}_{2}: \mathrm{N}, 12.83$; found: $\mathrm{N}, 12.70$.

An attempt to obtain pseudouric acid by condensation of this ester with urea, in the presence of sodium ethylate, was unsuccessful. This is apparently due to the fact that the sodium salt of diethyl ureidomalonate is extremely difficultly soluble in alcohol.

$$
\text { 2-Thio-6-oxy-4,5-diaminopyrimidine, }\left.\left.\right|_{\mathrm{NH}} ^{\mathrm{CS}}\right|_{\mathrm{CNH}_{2}} ^{\mathrm{NH}-\mathrm{NH}}
$$

was obtained by digesting an alcoholic solution of aminomalonic nitrile with thiourea and the required proportion of sodium ethylate. The alcoholic solution was boiled for 5 hours on the steam bath, and the pyrimidine isolated in the usual manner. It was purified by decolorization of its alkaline solution with bone coal and then precipitating from the alkaline solution with acetic acid. It had no definite decomposition point and after drying to constant weight at $100^{\circ}$ a nitrogen determination (Kjeldahl) gave the following result: The yield was small.

NEW HAVEN, CoNs.

[CONTRIBUTIONS FROM THE SHEFField ChEMICAL LABORATORY OF YalE UNIVERSTTY.] RESEARCHES ON HYDANTOINS. XXVII. SYNTHESIS OF HYDANTOIN-4-CARBOXAMIDE.

By Treat B. Johnson AND BEN H. NICOLET. Received November 24, 1913.

The mechanism of the reaction, by which alloxans are formed by the oxidation of uric acids, has been correctly interpreted by Biltz. This investigator has shown, in his recent work on the oxidation of purines, that these transformations (oxidation reactions) involve two independent 